University of South Carolina

Scholar Commons

$9-1-2007$

\title{
Silicon Dioxide-Encapsulated High-Voltage AIGaN/GaN HFETs for Power-Switching Applications
}

\author{
N. Tipirneni \\ University of South Carolina - Columbia, tipimen@engr.sc.edu \\ V. Adivarahan \\ University of South Carolina - Columbia \\ Grigory Simin \\ University of South Carolina - Columbia, simin@engr.sc.edu \\ Asif Khan \\ University of South Carolina - Columbia, asif@engr.sc.edu
}

Follow this and additional works at: https://scholarcommons.sc.edu/elct_facpub

Part of the Electrical and Computer Engineering Commons

\author{
Publication Info \\ Published in IEEE Electron Device Letters, Volume 28, Issue 9, 2007, pages 784-786. \\ http://ieeexplore.ieee.org/xpl/Recentlssue.jsp?punumber=55 \\ (C) 2007 by IEEE
}

This Article is brought to you by the Electrical Engineering, Department of at Scholar Commons. It has been accepted for inclusion in Faculty Publications by an authorized administrator of Scholar Commons. For more information, please contact digres@mailbox.sc.edu. 


\title{
Silicon Dioxide-Encapsulated High-Voltage AlGaN/GaN HFETs for Power-Switching Applications
}

\author{
N. Tipirneni, V. Adivarahan, G. Simin, Senior Member, IEEE, and A. Khan, Fellow, IEEE
}

\begin{abstract}
In this letter, new approach in achieving high breakdown voltages in AlGaN/GaN heterostructure field-effect transistors (HFETs) by suppressing surface flashover using solid encapsulation material is presented. Surface flashover in III-Nitride-based HFETs limits the operating voltages at levels well below breakdown voltages of $\mathrm{GaN}$. This premature gate-drain breakdown can be suppressed by immersing devices in highdielectric-strength liquids (e.g., Fluorinert); however, such a technique is not practical. In this letter, AlGaN/GaN HFETs encapsulated with PECVD-deposited $\mathrm{SiO}_{2}$ films demonstrated breakdown voltage of $900 \mathrm{~V}$, very similar to that of devices immersed in Fluorinert liquid. Simultaneously, low dynamic oN-resistance of $2.43 \mathrm{~m} \Omega \cdot \mathrm{cm}^{2}$ has been achieved, making the developed AlGaN/GaN HFETs practical high-voltage high-power switches for power-electronics applications.
\end{abstract}

Index Terms-AlGaN-GaN heterostructure field-effect transistor (HFET), breakdown voltage, field plate (FP), HEMT, high-voltage power device, surface flashover.

\section{INTRODUCTION}

$\mathbf{H}$ ETEROSTRUCTURE field-effect transistors (HFETs) based on $\mathrm{AlGaN} / \mathrm{GaN}$ show tremendous promise as switching elements for power-electronic applications. As common to all power semiconductor devices, achieving high breakdown voltages $V_{\mathrm{BR}}$ with minimum ON-resistance $R_{\mathrm{ON}}$ has also been the primary challenge for AlGaN/GaN HFETs. A common route taken to address this challenge in AlGaN/GaN HFETs was in optimizing the field profile in gate-drain region to sustain the highest possible operating voltage at the lowest $L_{\mathrm{GD}}$ value [1]-[8].

In the past, single or multiple field plates (FPs) (overlapping gate) have been implemented to increase breakdown voltages in AlGaN/GaN HFETs [2], [5], [6]. AlGaN/GaN HFET with multiple FPs demonstrated breakdown voltage of $900 \mathrm{~V}$ for a device with $L_{\mathrm{GD}}=24 \mu \mathrm{m}$ [6]. The mechanism of $V_{\mathrm{BR}}$ increase in FP devices is believed to be electric-field spike reduction at drain-side edge of the gate. Recent important findings show that, in HFET devices, either with or without FPs, the breakdown voltage is limited by surface flashover that occurs in air regions adjacent to gate-drain area and is not due to breakdown of III-Nitride material itself [10], [12], [13]. It has been shown that suppression of surface flashover by immersing the devices

Manuscript received June 7, 2007; revised June 26, 2007. The review of this letter was arranged by Editor J. del Alamo.

The authors are with the Department of Electrical Engineering, University of South Carolina, Columbia, SC 29208 USA (e-mail: tipirnen@engr.sc.edu).

Digital Object Identifier 10.1109/LED.2007.903910 in high-dielectric-strength liquid material Flourinert results in linear $V_{\mathrm{BR}}-L_{\mathrm{GD}}$ dependence, reaching breakdown voltages above $1.5 \mathrm{kV}$ at $L_{\mathrm{GD}}=20 \mu \mathrm{m}$. Linear $V_{\mathrm{BR}}-L_{\mathrm{GD}}$ dependence by immersion in Flourinert clearly demonstrates the feasibility of achieving very high breakdown voltages in $\mathrm{AlGaN} / \mathrm{GaN}$ HFETs. However, such method can hardly be considered as a practical way of fabricating devices for high-voltage power converters. Hence, it is important to find an alternative way to suppress surface flashover without the need of immersing the devices in the liquid.

In this letter, we present a detailed study of $\mathrm{AlGaN} / \mathrm{GaN}$ HFET breakdown voltages with different encapsulation materials to show that high-dielectric-strength solid insulating films can be successfully used to suppress surface flashover.

\section{EXPERIMENTAL DETAILS}

AlGaN/GaN HFETs used for this letter were grown on sapphire substrates by low-pressure MOCVD. The device epilayer structure consisted of 15-nm-thick low-temperaturegrown AlN buffer layer followed by $1-\mu \mathrm{m}$-thick undoped $\mathrm{GaN}$ layer, which was capped with $25-\mathrm{nm} \mathrm{Al}_{0.25} \mathrm{Ga}_{0.75} \mathrm{~N}$ barrier layer. Device fabrication started with mesa etching, Ti/Al/Ti/Au ohmic contact deposition and annealing followed by Ni/Au gate formation. The gate length $L_{G}=2 \mu \mathrm{m}$ and gate-source spacing $L_{\mathrm{GS}}=2 \mu \mathrm{m}$ were kept constant, whereas the gatedrain spacing $L_{\mathrm{GD}}$ varied from 2 to $20 \mu \mathrm{m}$. The gate width was $W_{G}=100 \mu \mathrm{m}$. The layer sheet resistance $R_{\mathrm{SH}}=350 \Omega / \mathrm{sq}$ and contact resistance $R_{C}=1 \Omega-\mathrm{mm}$ were measured using standard transmission-line-model procedure. The threshold voltage was $V_{T}=-4.5 \mathrm{~V}$, and saturation current at zero gate bias for fabricated devices was $0.6 \mathrm{~A} / \mathrm{mm}$. The device $I-V$ characteristics are given as inset in Fig. 2(a).

\section{Results AND Discussion}

The breakdown voltage measured using Tektronix 370A curve tracer was defined as the drain voltage at which drain-current exceeds $1 \mathrm{~mA} / \mathrm{mm}$ with gate biased below threshold voltage. As-fabricated (AF) devices (unpassivated and with out FP) were tested for breakdown voltages in air and in Fluorinert ambience. As shown in Fig. $1, V_{\mathrm{BR}}-L_{\mathrm{GD}}$ curve for Flourinert ambience (open diamonds) yields a breakdown voltage of $900 \mathrm{~V}$ at $L_{\mathrm{GD}}=20 \mu \mathrm{m}$. The corresponding ONresistance is $R_{\mathrm{ON}}=2.43 \mathrm{~m} \Omega \cdot \mathrm{cm}^{2}$. However, these $R_{\mathrm{ON}}$ values correspond to static device $I-V$ characteristics only. 


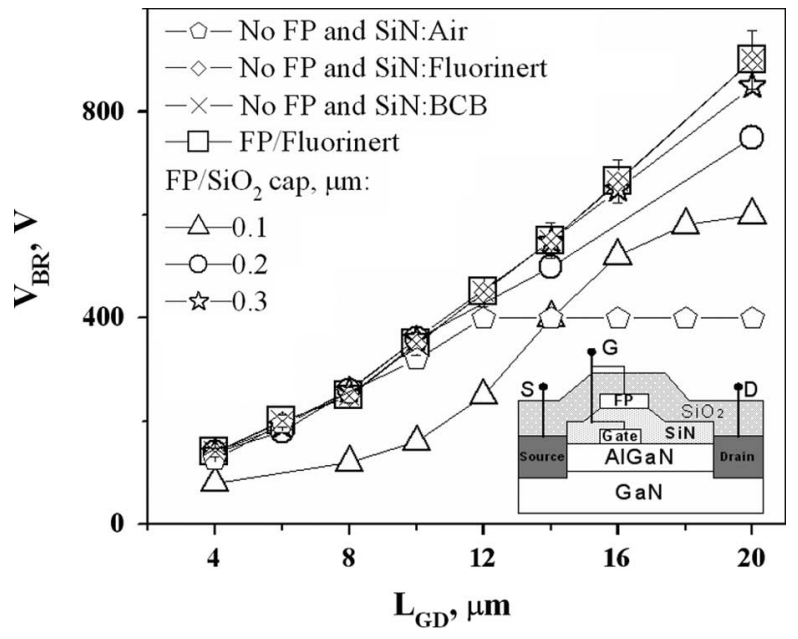

Fig. 1. $V_{\mathrm{BR}}-L_{\mathrm{GD}}$ dependence of $\mathrm{AF}$ and $\mathrm{FP} \mathrm{AlGaN} / \mathrm{GaN}$ HFETs in Fluorinert ambient and when encapsulated in varying thickness PECVDdeposited $\mathrm{SiO}_{2} / \mathrm{BCB}$. The inset shows schematic layout of $\mathrm{SiO}_{2}$-encapsulated FP-HFET.

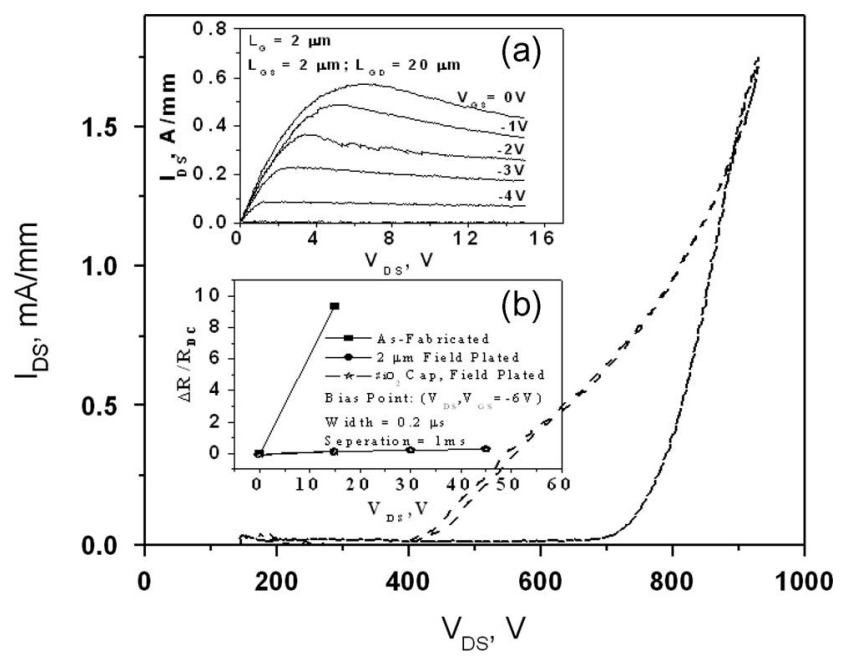

Fig. 2. OFF-state drain-current $\left(V_{\mathrm{GS}}=-6 \mathrm{~V}\right)$ for a $20-\mu \mathrm{m}$ gate-drain spacing device. The inset (a) shows de $I-V$ of AlGaN/GaN HFET and (b) shows relative increase in dynamic ON-resistance with respect to dc ON-resistance for AF and FP-HFETs. The dynamic ON-resistance has been measured by taking the device pulsed current-voltage characteristics immediately after application of different drain voltage pulses. A pulse width of $0.2 \mu \mathrm{s}$ and the pulse period of $1 \mathrm{~ms}$ were used.

As shown in Fig. 2(b), due to large-signal dispersion (also referred to as current collapse), these AF devices have the dynamic ON-resistance, which significantly exceeds static values and, thus, cannot be used for switching applications.

In order to suppress current collapse and achieve lowdynamic ON-resistance, the devices were subsequently passivated and FP. First, $0.1-\mu$ m-thick $\mathrm{Si}_{3} \mathrm{~N}_{4}$ passivation layer was deposited. Next, Ni/Au FP with $2-\mu$ m overhang toward the drain was deposited on top of $\mathrm{Si}_{3} \mathrm{~N}_{4}$ passivation layer; this was connected to the gate-contact pad through an opening in passivation layer. As shown in Fig. 2(b), FP-HFETs show minimal increase in dynamic ON-resistance. The devices were then tested for breakdown voltages in Fluorinert ambient. As shown in Fig. 1, the measured $V_{\mathrm{BR}}-L_{\mathrm{GD}}$ data of FP-devices

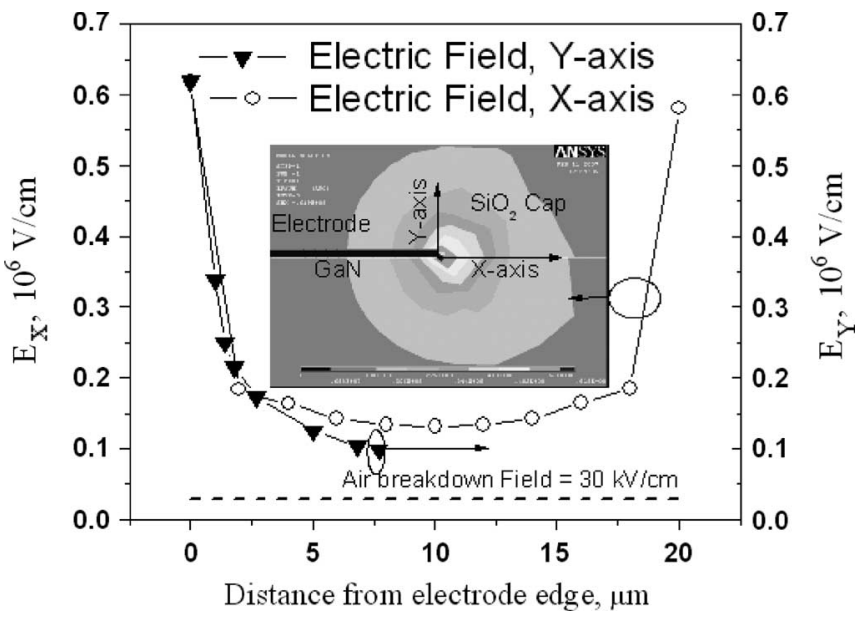

Fig. 3. Simulated electric-field distribution (in volts per centimeter) between two electrodes $20 \mu \mathrm{m}$ apart sitting on top of $\mathrm{GaN}\left(\varepsilon_{r}=9\right)$ with $25-\mu \mathrm{m} \mathrm{SiO}_{2}\left(\varepsilon_{r}=4\right)$ surrounding the electrodes using ANSYS. The potential difference between the electrodes is $400 \mathrm{~V}$. The field along the $x$-axis in the figure corresponds to the field along $\mathrm{GaN} / \mathrm{SiO}_{2}$ boundary in the electrode plane between the electrodes and the field along the $y$-axis corresponds to the field along the gate/electrode edge in to $\mathrm{SiO}_{2}$ layer.

(open squares) were identical to those of $\mathrm{AF}$ devices yielding a breakdown voltage of around $900 \mathrm{~V}$ at $L_{\mathrm{GD}}=20 \mu \mathrm{m}$ in Fluorinert.

As discussed in [12] and confirmed by devices described above, the effect of different design features on HFET switch performance can be summarized as follows. The SiN passivation mitigates current collapse and allows for low dynamic ON-resistance; however, it causes high gate-leakage currents reducing breakdown voltages to $100-200 \mathrm{~V}$. FP limits this SiN-induced gate-leakage-current-increasing breakdown voltage of passivated devices. However, breakdown voltages of FP-HFETs are still limited by surface flashover. Hence, highdielectric-strength encapsulation of FP-HFETs to suppress surface flashover is needed to achieve high-breakdown-voltage low ON-resistance performance.

For obvious reasons, solid encapsulating materials are much more preferable for practical device fabrication and packaging than liquid Fluorinert. An ideal encapsulation layer should have breakdown fields exceeding those of $\mathrm{GaN}$ and $\mathrm{AlGaN}$ (around $3 \mathrm{MV} / \mathrm{cm}$ ). Among the reported materials meeting, these criteria are PECVD-deposited $\mathrm{Si}_{3} \mathrm{~N}_{4}(3-12 \mathrm{MV} / \mathrm{cm})$ [14] and $\mathrm{SiO}_{2}(3-12 \mathrm{MV} / \mathrm{cm})$ [15]. For presented studies, we chose silicon-dioxide films as the encapsulation material because of its low dielectric constant $\left(\varepsilon_{r}=3.9\right)$ as compared to that of $\operatorname{SiN}\left(\varepsilon_{r}=7.5\right)$, which leads to a lower gate capacitance and, correspondingly, to lower switching losses.

One of the key parameters determining performance of HFET with solid encapsulation is the required thickness of dielectric cap layer. In order to estimate the minimal dielectricfilm thickness required for effective encapsulation, we have carried out 2-D simulations using ANSYS software package of lateral and transverse electric-field distribution between two electrodes with $20-\mu \mathrm{m}$ spacing laid out on top of GaN $\left(\varepsilon_{r}=\right.$ 9) and capped with $25-\mu \mathrm{m} \mathrm{SiO}_{2}\left(\varepsilon_{r}=4\right)$ film. As shown in Fig. $3, \mathrm{SiO}_{2}$ encapsulation layer thicker than $5 \mu \mathrm{m}$ is needed 
for peak electric field around the electrodes to drop below the air breakdown field of $0.03 \mathrm{MV} / \mathrm{cm}$ for an applied potential of $400 \mathrm{~V}$ between electrodes.

Next, we carried out an experimental study of FP $\mathrm{AlGaN} / \mathrm{GaN}$ HFETs with different thickness of encapsulated $\mathrm{SiO}_{2}$ films. The devices were first encapsulated with $0.1-\mu \mathrm{m}-$ thick PECVD-deposited $\mathrm{SiO}_{2}$ film. After that, $V_{\mathrm{BR}}-L_{\mathrm{GD}}$ dependence was measured, and the next $0.1-\mu \mathrm{m}$ encapsulation layer was deposited. The results for FP devices with different $\mathrm{SiO}_{2}$ cap film thickness are compared in Fig. 1. As shown, 0.1and $0.2-\mu \mathrm{m}$-thick films were not able to completely suppress the premature breakdown. However, deposition of $0.3-\mu \mathrm{m}$-thick $\mathrm{SiO}_{2}$ film resulted in almost the same $V_{\mathrm{BR}}-L_{\mathrm{GD}}$ curve as in Fluorinert ambience suggesting aimed suppression of surface flashover by $0.3-\mu \mathrm{m} \mathrm{SiO}{ }_{2}$ encapsulation. A consistently high breakdown voltage of 850-900 V was measured over several 0.3 - $\mu$ m-thick $\mathrm{SiO}_{2}$-encapsulated devices with $L_{\mathrm{GD}}=20 \mu \mathrm{m}$ in air ambience. As shown in Fig. 2(b), the $\mathrm{SiO}_{2}$ encapsulation has no negative effect on the dynamic ON-resistance. Fig. 2 shows the OFF-state drain-current $\left(V_{\mathrm{GS}}=-6 \mathrm{~V}\right)$ for $20-\mu \mathrm{m}$ gatedrain spacing device. The devices also showed no change in the leakage current proving $\mathrm{SiO}_{2}$-encapsulated $\mathrm{FP} \mathrm{AlGaN} / \mathrm{GaN}$ HFETs to be a strong candidate for high-voltage low-ONresistance switches.

Note that, in our experiments, we have not observed the air flashover, although $0.3-\mu \mathrm{m} \mathrm{SiO}_{2}$ encapsulation is certainly not thick enough to completely absorb the high-field region near gate electrode, as follows from 2-D simulations. Possible explanation of observed results is related to the mechanism of avalanche-breakdown development in air. As shown in [16], ions formed during ionization of air accelerate and hit the surface of insulating encapsulating material charging it. The charge accumulation at insulator-air interface decreases the interface field ultimately, extinguishing the plasma. As the field in plasma reduces, field inside the insulating film increases. Thus, electric field inside the insulator defines the minimum thickness of insulator required to suppress air flashover and explains observed $\mathrm{AlGaN} / \mathrm{GaN}$ HFET $V_{\mathrm{BR}}-L_{\mathrm{GD}}$ thickness dependence.

Finally, 2-3- $\mu$ m-thick cured Bisbenzocyclobutene (BCB) with high dielectric strength of 3-5 MV/cm [17] was also found to be effective in suppressing the premature gate-drain breakdown and achieving high breakdown voltages in $\mathrm{AF}$ AlGaN/GaN HFETs, very close to those in Fluorinert. BCB has advantages of low dielectric constant $\left(\varepsilon_{r}=2.65-2.5\right)$, low moisture intake, and simple processing. The limitation associated with BCB encapsulation is its relatively low operating temperature of $350{ }^{\circ} \mathrm{C}$; the active-region temperature in high-power III-N HFETs can exceed this limit due to selfheating [18].

\section{CONCLUSION}

The suppression of premature breakdown due to surface flashover in AlGaN/GaN HFETs has been achieved using PECVD-deposited $\mathrm{SiO}_{2}$ film encapsulation. It has been found that $0.3-\mu \mathrm{m}$-thick film can effectively suppress the flashover for $20-\mu \mathrm{m}$ gate-drain separation, resulting in $900-\mathrm{V}$ $2.43-\mathrm{m} \Omega \cdot \mathrm{cm}^{2}$ dynamic ON-resistance FP AlGaN/GaN
HFETs. Similar high-breakdown-voltage AlGaN/GaN HFETs have been obtained using 2- $\mu \mathrm{m}$-thick BCB film encapsulation. These results demonstrate practical approach to making high-voltage III-Nitride switching devices for power-converter applications.

\section{REFERENCES}

[1] S. Karmalkar, J. Deng, M. S. Shur, and R. Gaska, "RESURF AlGaN-GaN HEMT for high voltage power switching," IEEE Electron Device Lett., vol. 22, no. 8, pp. 373-375, Aug. 2001.

[2] N.-Q. Zhang, S. Keller, G. Parish, S. Heikman, S. P. Denbaars, and U. K. Mishra, "High breakdown GaN HEMT with overlapping gate structure," IEEE Electron Device Lett., vol. 21, no. 9, pp. 421-423, Sep. 2000.

[3] G. Simin, X. Hu, N. Ilinskaya, A. Kumar, A. Koudymov, J. Zhang, M. Asif Khan, R. Gaska, and M. S. Shur, "A $7.5 \mathrm{~kW} / \mathrm{mm}_{2}$ current switch using $\mathrm{AlGaN} / \mathrm{GaN}$ metal-oxide-semiconductor heterostructure field effect transistors on SiC substrates," Electron. Lett., vol. 36, no. 24, pp. 2043-2044, Nov. 2000.

[4] N.-Q. Zhang, B. Moran, S. P. Denbaars, U. K. Mishra, X. W. Wang, and T. P. Ma, "Kilovolt AlGaN/GaN HEMTs as switching devices," Phys. Stat. Sol., A, vol. 188, no. 1, pp. 213-217, Nov. 2001.

[5] W. Saito, Y. Takada, M. Kuraguchi, K. Tsuda, I. Omura, T. Ogura, and H. Ohashi, "High breakdown voltage AlGaN-GaN power-HEMT design and high current density switching behavior," IEEE Trans. Electron Devices, vol. 50, no. 12, pp. 2528-2531, Dec. 2003.

[6] H. Xing, Y. Dora, A. Chini, S. Heikman, S. Keller, and U. K. Mishra, "High breakdown voltage AlGaN-GaN HEMTs achieved by multiple field plates," IEEE Electron Device Lett., vol. 25, no. 4, pp. 161-163, Apr. 2004.

[7] R. Gaska, Q. Chen, J. Yang, A. Osinsky, M. A. Khan, and M. S. Shur, "AlGaN/GaN heterostructure FETs with offset gate design," Electron. Lett., vol. 33, no. 14, pp. 1255-1257, Jul. 1997.

[8] N. Zhang, V. Mehrotra, S. Chandrasekaran, B. Moran, L. Shen, U. Mishra, E. Etzkorn, and D. Clarke, "Large area GaN HEMT power devices for power electronic applications: Switching and temperature characteristics," in Proc. PESC, 2003, pp. 233-237.

[9] W. R. Frensley, "Power-limiting breakdown effects in GaAs MESFETs," IEEE Trans. Electron Devices, vol. ED-28, no. 8, pp. 962-970, Aug. 1981.

[10] N. Tipirneni, A. Koudymov, V. Adivarhan, J. Yang, G. Simin, and M. A. Khan, "The $1.6 \mathrm{kV}$ AlGaN/GaN HFETs," IEEE Electron Device Lett., vol. 27, no. 9, pp. 716-718, Sep. 2006.

[11] W. S. Tan, M. J. Uren, P. A. Houston, R. T. Green, R. S. Balmer, and T. Martin, "Surface leakage currents in $\mathrm{SiN}_{x}$ passivated AlGaN/GaN HFETs," IEEE Electron Device Lett., vol. 27, no. 1, pp. 161-163, Jan. 2006.

[12] N. Tipirneni, A. Koudymov, V. Adivarahan, J. Yang, G. Simin, and M. Asif Khan, "Low dynamic on-resistance kilovolt-range AlGaN/GaN HFETs," in Proc. Device Res. Conf., University Park, PA, Jun. 26-28, 2006, pp. 109-110.

[13] Y. Dora, A. Chakraborty, L. McCarthy, S. Keller, S. P. DenBaars, and U. K. Mishra, "High breakdown voltage achieved on AlGaN/GaN HEMTs with integrated slant field plates," IEEE Electron Device Lett., vol. 27, no. 9, pp. 713-715, Sep. 2006.

[14] W. C. H. Ng, K. W. Chew, and S. F. Chu, "Characterization and comparison of PECVD silicon nitride and silicon oxynitride dielectric for MIM capacitors," IEEE Electron Device Lett., vol. 24, no. 8, pp. 506-508, Aug. 2003.

[15] J. S. Herman and F. L. Terry, "A two-temperature technique for PECVD deposition of silicon dioxide," IEEE Electron Device Lett., vol. 12, no. 5, pp. 236-237, May 1991.

[16] S. A. Campbell, The Science and Engineering of Microelectronic Fabrication, 2nd ed. New York: Oxford Univ. Press, 2001.

[17] BCB which is commercially marketed by Dow Chemicals as CYCLOTENE. The materials data sheet, properties and the recommended processing methods are listed at. [Online]. Available: http://www. dow.com/cyclotene/

[18] M. Kuball, G. J. Riedel, J. W. Pomeroy, A. Sarua, M. J. Uren, T. Martin, K. P. Hilton, J. O. Maclean, and D. J. Wallis, "Time-resolved temperature measurement of $\mathrm{AlGaN} / \mathrm{GaN}$ electronic devices using micro-Raman spectroscopy," IEEE Electron Device Lett., vol. 28, no. 2, pp. 86-89, Feb. 2007. 